\title{
Method development for acetyl octapeptide-3 analysis by liquid chromatography-tandem mass spectrometry
}

Moongi $\mathrm{Ji}^{1+}$, Hyeon-Seong Lee ${ }^{1+}$, Youngbae Kim ${ }^{1}$, Chan Seo ${ }^{2}$, Subin $\mathrm{Choi}^{3}$, Songjin Oh${ }^{1}$, Jeuk Min ${ }^{1}$, Hyung-Jin Park ${ }^{1}$, Jung Dong Kim ${ }^{4}$, Do Hyeon Jeong ${ }^{4}$ and Man-Jeong Paik ${ }^{1 *}$

\begin{abstract}
Background: Acetyl octapeptide-3 (SNAP-8) is an antiaging peptide that is more effective than acetyl hexapeptide3 , which is more stable than botulinum toxin and effectively relieves facial wrinkles. Products containing SNAP-8 such as patch are producing, but analytical method has not been reported to determination of SNAP-8.

Method: Mobile phase, collision energy, and desolvation line temperature were optimized, and mass spectral data set for SNAP-8 was newly constructed by liquid chromatography-triple quadrupole mass spectrometer in multiple reaction monitoring mode.

Results: The developed method showed good linearity ( $r \geq 0.9971)$ with limit of quantification of $0.0125 \mathrm{ng} / \mathrm{mL}$, repeatability (\% relative standard deviation $=0.02$ to 0.12 ) and accuracy (\% relative error $=-1.68$ to 1.44 ) under optimal conditions. This method was successfully applied to a biodegradable microneedle patch loaded with SNAP-8.

Conclusion: The present method for the quantification of SNAP-8 may be useful for quality control in the cosmetic fields. Keywords: Acetyl octapeptide-3, Microneedle Patch, Multiple reaction monitoring mode, Liquid chromatography-tandem mass spectrometry
\end{abstract}

\section{Introduction}

The synaptosome-associated protein of $25 \mathrm{kDa}$ (SNAP25) is known to relate to facial wrinkles including muscle contraction (Adler et al. 2001). The acetyl hexapeptide- 3 is a peptide fragment of SNAP-25 and it has been widely used for the cosmetic materials of the improvement of facial wrinkles because acetyl hexapeptide has an inhibiting effect on the function of SNAP-25 $\left(\right.$ Lipotec $\left.^{\mathrm{Tm}}\right)$. An acetyl octapeptide-3 (SNAP-8) added a two-amino acid chain on acetyl hexapeptide-3, which was designed for better effect of wrinkle improvement

\footnotetext{
* Correspondence: paik815@sunchon.ac.kr

${ }^{+}$Moongi Ji and Hyeon-Seong Lee contributed equally to this work.

${ }^{1}$ College of Pharmacy, Sunchon National University, Suncheon 540-950,

Republic of Korea

Full list of author information is available at the end of the article
}

than acetyl hexapeptide-3 $\left(\right.$ Lipotec $\left.^{\mathrm{TN}}\right)$. A botulinum toxin $\left(\mathrm{BOTOX}^{\circ}\right)$ has been widely used for the improvement of facial wrinkles, but SNAP-8 has higher safety than BOTOX $^{\circ}$ (Blanes-Mira et al. 2002; Zhou et al. 2011). Both SNAP-8 and a botulinum toxin $\left(\mathrm{BOTOX}^{\circ}\right)$ target the SNAP-25. BOTOX ${ }^{\circ}$ breaks the SNAP-25 and causes muscle paralysis, while SNAP-8 captures the SNAP-25 and causes muscle relaxation (Blasi et al. 1993; Gutiérrez et al. 1995; Gutierrez et al. 1997; Blanes-Mira et al. 2002; Yamauchi and Lowe 2004). Thus, SNAP-8 is more stable than BOTOX $^{\oplus}$, which has been proposed as a functional cosmetic material that can replace BOTOX ${ }^{\circ}\left(\right.$ Lipotec $^{\mathrm{Tm}}$; Blanes-Mira et al. 2002). Although SNAP-8 is being used in functional cosmetics, method for SNAP-8

\section{Springer Open}

(๑) The Author(s). 2020 Open Access This article is licensed under a Creative Commons Attribution 4.0 International License, which permits use, sharing, adaptation, distribution and reproduction in any medium or format, as long as you give appropriate credit to the original author(s) and the source, provide a link to the Creative Commons licence, and indicate if changes were made. The images or other third party material in this article are included in the article's Creative Commons licence, unless indicated otherwise in a credit line to the material. If material is not included in the article's Creative Commons licence and your intended use is not permitted by statutory regulation or exceeds the permitted use, you will need to obtain permission directly from the copyright holder. To view a copy of this licence, visit http://creativecommons.org/licenses/by/4.0/. 
<smiles>CSCCC(NC(=O)C(CCC(=O)O)NC(=O)C(CCC(=O)O)NC(C)=O)C(=O)NC(CCC(C)=O)C(=O)NC(CCCNC(N)=O)C(=O)NC(CCCNC(=N)N)C(=O)NC(C)C(=O)N[C@@H](CC(=O)O)C(N)=O</smiles>

MW: 1075

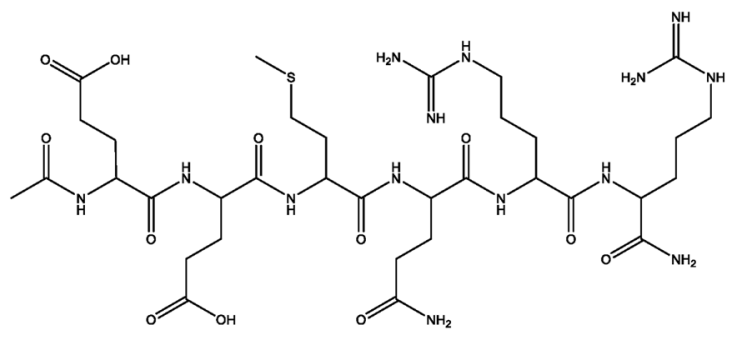

Acetylhexapeptide-3 (IS)

MW: 889

Seq : Acetyl-Glu-Glu-Met-Gln-Arg-Arg- $\mathrm{NH}_{2}$

Fig. 1 Chemical structures of SNAP-8 and IS

analysis has not been reported. Patches are generally used as an example of skin delivery products. Polymeric compounds such as peptides cannot pass through the stratum corneum and skin absorption is also difficult (Park et al. 2005). However, microneedle patches penetrate the dermal layer and can transfer substances such as SNAP-8 with large molecular weights directly into skin, which were used for the transdermal delivery of polymeric compounds (Zhang et al. 2014). In this study, analytical method of SNAP-8 was developed by liquid chromatographytandem mass spectrometry (LC-MS/MS). This method was successfully applied to quantification of SNAP-8 level in biodegradable microneedle patches.

\section{Materials and methods}

\section{Materials}

SNAP-8 and the acetyl hexapeptide-3 as internal standard (IS) were purchased from Lipotec (Barcelona, Spain); their chemical structures are shown in Fig. 1. Biodegradable microneedle patches containing SNAP-8 were provided by Raphas Co. Ltd. (Seoul, Republic of Korea). Highperformance liquid chromatography (HPLC) grade water and acetonitrile $(\mathrm{ACN})$ were purchased from Daejung Chemical (Siheung-si, Gyeonggi-do, Republic of Korea). The syringe-driven filter unit $(0.45 \mu \mathrm{m})$ was purchased from Merck Millipore (Darmstadt, Germany). Formic acid (FA) and trimethylamine (TEA) were purchased from Wako Pure Chemical (Richmond, VA, USA). All other chemicals were of analytical reagent grade.

\section{Preparation of standard and calibration solutions}

Stock solutions of SNAP-8 and IS were made up at $10.0 \mu \mathrm{g} / \mu \mathrm{L}$ in HPLC grade water. Working standard solutions were prepared by diluting each stock solution to $12.5 \mathrm{ng} / \mu \mathrm{L}$ (SNAP-8) and $15.0 \mathrm{ng} / \mu \mathrm{L}$ (IS), respectively. The SNAP-8 standards for quantitative calibration curve were prepared from 0.0125 to 0.15 $\mathrm{ng} / \mu \mathrm{L}$ by aliquots of each working standard solution. All standard solutions were then stored at $4{ }^{\circ} \mathrm{C}$.

\section{Preparation of microneedle patches}

Biodegradable microneedle of patch $(1.42 \mathrm{mg})$ with loaded SNAP-8 was extracted with distilled water $(5 \mathrm{~mL})$ containing IS $(150.0 \mathrm{ng})$. The extract was filtered with syringe-driven filter unit $(0.45 \mu \mathrm{m})$, then an aliquot of $10 \mu \mathrm{L}$ was injected into the LC-MS/MS system.

\section{Method validation for SNAP-8 analysis}

Linearity, repeatability, accuracy, recovery, limit of detection (LOD), and limit of quantification (LOQ) were validated under optimal conditions with blank patch matrix. Calibration dynamic range was performed from 0.0125 to $0.15 \mathrm{ng} / \mu \mathrm{L}$. Slope, intercept, and correlation coefficient $(r)$ were determined by using the least-squares regression analysis form the calibration curve constructed based on relative peak area ratios to IS. LOD was evaluated by injection following dilution with standard solution at the

Table 1 Comparison of ionic strength between TFA and FA as additives in the mobile phase

\begin{tabular}{lll}
\hline Name & Area & \\
\cline { 2 - 3 } & $0.125 \mathrm{ng} / \mu \mathrm{L}(n=5)$ & $0.5 \mathrm{ng} / \mu \mathrm{L}(n=5)$ \\
\hline $0.1 \%$ TFA & \\
SNAP-8 & $11,916 \pm 1171$ & $44,438 \pm 1672$ \\
IS & $30,991 \pm 2577$ & $27,287 \pm 1558$ \\
0.1\% FA & & \\
SNAP-8 & $75,020 \pm 1636$ & $305,665 \pm 3459$ \\
IS & $242,824 \pm 9473$ & $251,054 \pm 2408$ \\
\hline
\end{tabular}



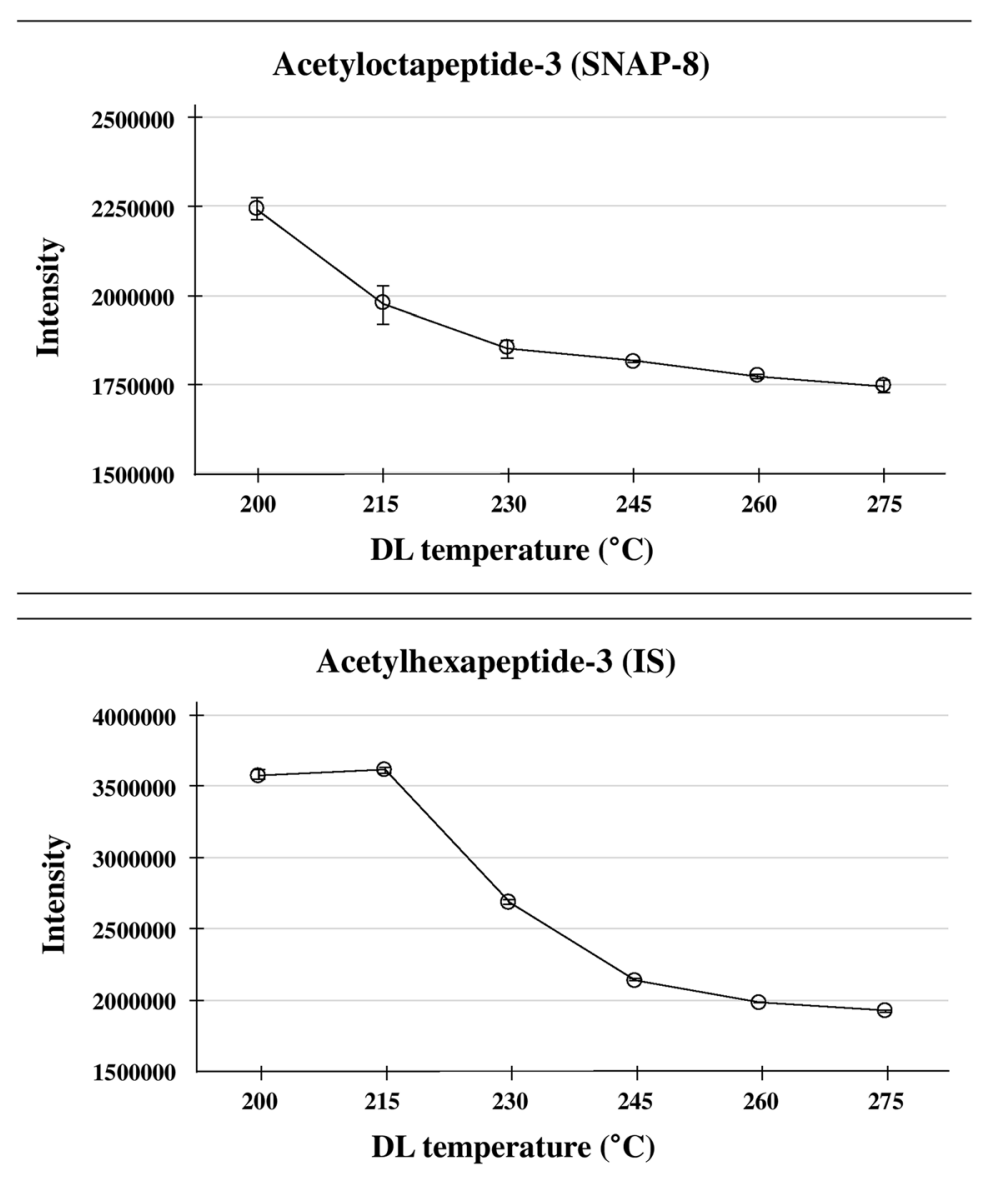

Fig. 2 Optimization of DL temperature in the range 200 to $275^{\circ} \mathrm{C}$

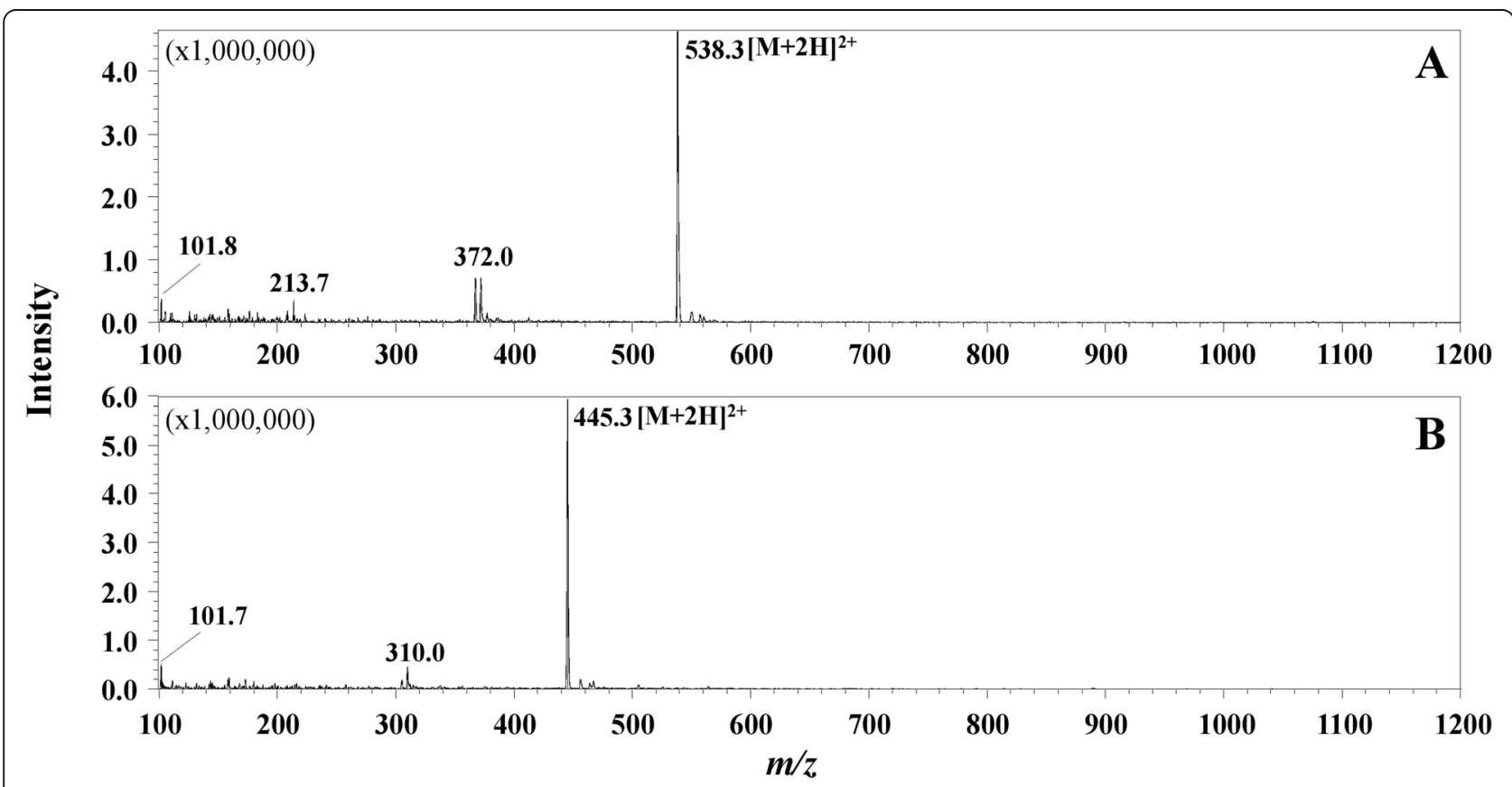

Fig. 3 Mass spectral patterns of SNAP-8 (a) and the IS (b) by LC-MS/MS with ESI mode 
Table 2 lon transitions and collision energy values of SNAP-8 and IS

\begin{tabular}{|c|c|c|c|c|c|c|c|}
\hline \multirow[t]{2}{*}{ Analyte } & \multirow{2}{*}{$\begin{array}{l}\text { Precursor } \\
\text { ion }[\mathrm{M}+ \\
2 \mathrm{H}]^{2+}(\boldsymbol{m} / \\
\boldsymbol{z})\end{array}$} & \multicolumn{6}{|l|}{ Product ions $(\boldsymbol{m} / \mathbf{z})$} \\
\hline & & Transition $1^{\mathbf{a}}(\mathbf{m} / \mathbf{z})$ & $C E 1^{c}(V)$ & Transition $2^{\mathbf{b}}(\mathbf{m} / \mathbf{z})$ & $\operatorname{CE}^{\mathbf{c}}(\mathrm{V})$ & Transition $3^{\mathbf{b}}(\mathbf{m} / \mathbf{z})$ & $\operatorname{CE3}^{c}(V)$ \\
\hline Acetyloctapeptide-3 (SNAP-8) & 538 & 102 & -30 & 84 & -48 & 144 & -25 \\
\hline Acetylhexapeptide-3 (IS) & 445 & 102 & -39 & 84 & -55 & 144 & -30 \\
\hline
\end{tabular}

${ }^{\mathrm{a}}$ Quantification ion

${ }^{\mathrm{b}}$ Qualitative ions

${ }^{\mathrm{c} C o l l i s i o n}$ energy

minimum concentration of calibration range. LOQ of SNAP-8 was defined as minimum concentration in the calibration range. The repeatability as relative standard deviation (\%RSD) and the accuracy as relative error (\%RE) were obtained from two different concentrations from triplicate experiments under the optimal conditions. The recovery was evaluated by comparing the percentages of peak area ratio of filtered to that of non-filtered sample (recovery of $100 \%$ ) including same concentration of SNAP-8.

\section{Liquid chromatography-tandem mass spectrometry}

LC-MS/MS analysis was performed in multiple reaction monitoring (MRM) mode using a Shimadzu
Nexera UPLC system (Shimadzu Corp., Kyoto, Japan) coupled with a LCMS-8050 triple quadrupole mass spectrometer (Shimadzu Corp., Kyoto, Japan) equipped with an electrospray ionization (ESI) interface in positive ionization mode. Chromatographic separation was performed using a betabasic- 18 column $(30 \mathrm{~mm} \times 2.1 \mathrm{~mm}, 5 \mu \mathrm{m}, 150 \AA$, Thermo Electron, Waltham, MA) equipped with a betabasic-18 guard column $(10 \mathrm{~mm} \times 2.1 \mathrm{~mm}, 5 \mu \mathrm{m}, 150 \AA$, Thermo Electron, Waltham, MA), which separates polar peptides like SNAP-8 in reverse phase mode. The column oven was maintained at $40^{\circ} \mathrm{C}$ and the autosampler temperature at $4{ }^{\circ} \mathrm{C}$. Gradient elution was performed using solvent A (HPLC grade water

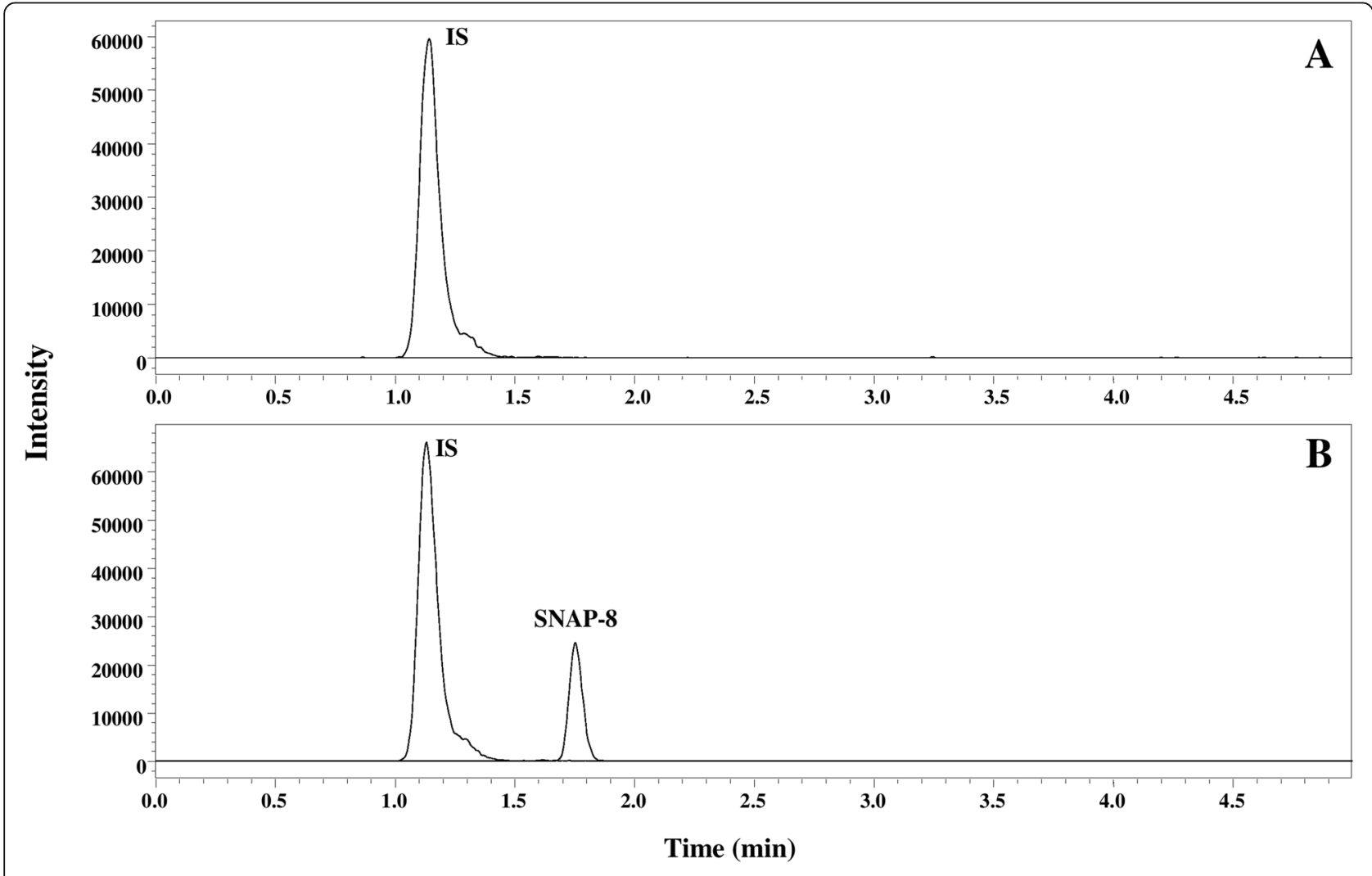

Fig. 4 MRM chromatograms of the blank spiked with IS (a) and SNAP-8 and IS (b) by LC-MS/MS 
Table 3 Validation data set of SNAP-8 by LC-MS/MS

\begin{tabular}{|c|c|c|c|c|c|c|c|c|c|}
\hline \multirow[t]{3}{*}{ Analyte } & \multirow{3}{*}{$\begin{array}{l}\text { Calibration } \\
\text { range (ng/ } \\
\text { mg of } \\
\text { microneedle } \\
\text { of patch) }\end{array}$} & \multirow{3}{*}{$\begin{array}{l}\text { Linearity } \\
(\boldsymbol{r})\end{array}$} & \multirow[t]{3}{*}{$\mathrm{LOD}^{\mathbf{a}}$} & \multirow[t]{3}{*}{$\mathrm{LOQ}^{\mathbf{b}}$} & \multicolumn{2}{|c|}{ Repeatability ${ }^{\mathbf{c}}(\%)$} & \multicolumn{2}{|c|}{ Accuracy $^{\mathbf{d}}(\%)$} & \multirow[t]{2}{*}{ Recovery ${ }^{\mathbf{e}}(\%)$} \\
\hline & & & & & \multicolumn{4}{|c|}{ Added (ng/mg of microneedle of patch) } & \\
\hline & & & & & 0.05 & 0.1 & 0.05 & 0.1 & 0.125 \\
\hline Acetyloctapeptide- & $0.0125-0.125$ & 0.9971 & 0.0025 & 0.0125 & 0.12 & 0.02 & 1.44 & -1.68 & 76.7 \\
\hline
\end{tabular}

3 (SNAP-8)

a $L O D$, limit of detection

bLOQ, limit of quantification

${ }^{\mathrm{C}}$ Relative standard deviation (\% RSD)

${ }^{\mathrm{d}}$ Relative error (\% RE)

${ }^{\mathrm{e}}$ Recovery (filtered/non-filtered) $\times 100$

containing $0.1 \% \mathrm{FA}$ ) and solvent $\mathrm{B}$ (ACN containing $0.1 \% \mathrm{FA}$ ) in total flow rate of $0.3 \mathrm{~mL} / \mathrm{min}$. Gradient condition of solvent B was initiated from $0 \%(0.5 \mathrm{~min})$ and was increased up to $40 \%$ ( 0.5 to $5 \mathrm{~min}$ ), and then held for $1 \mathrm{~min}$ (5 to $6 \mathrm{~min}$ ), and then return to the initial condition for the next run and hold for $2 \mathrm{~min}$ (6 to $8 \mathrm{~min}$ ). An aliquot $10 \mu \mathrm{L}$ of each sample was injected into the LC-MS/MS system. The mass spectrometer interface temperature was maintained at $200{ }^{\circ} \mathrm{C}$, the nebulizing gas flow was at $3.0 \mathrm{~L} / \mathrm{min}$, desolvation line $(\mathrm{DL})$ temperature at $200^{\circ} \mathrm{C}$, and heat block temperature at $400^{\circ} \mathrm{C}$. The pressure of collision-induced dissociation (CID) gas was at 270 $\mathrm{kPa}$. SNAP-8 and IS were successfully detected in the product-ion scan mode. Quantitative analyses were performed in the MRM transition mode with quadrupole $1(\mathrm{Q} 1)$ and quadrupole $3(\mathrm{Q} 3)$ operated at unit resolution. A dwell time and pause time were set at $22.0 \mathrm{~ms}$ for selected ions.

\section{Result and discussion}

Optimal conditions for SNAP-8 analysis by LC-MRM-MS/MS

The effects of FA and TEA as additives in the mobile phase were investigated. In this result, FA was used due to higher intensity (about six times) than those of TEA (Table 1). A $\mathrm{C}_{18}$-column $(5 \mu \mathrm{m}, 150 \AA)$ with equipped a guard column was selected for peptide analysis. Analysis of SNAP-8 was performed using gradient elution within 2 $\mathrm{min}$. The precursor ions of SNAP-8 and IS were selected with each multiply charged ion in ESI mode. The $[\mathrm{M}+$ $2 \mathrm{H}]^{2+}$ ions of SNAP-8 $(\mathrm{m} / z$ 538) and IS $(\mathrm{m} / z$ 445) were selected as precursor multiple ions in positive mode. The $[\mathrm{M}+\mathrm{H}]^{+}$ions of SNAP-8 $(m / z 1076)$ and IS $(m / z 890)$ were detected at low intensities and the $[\mathrm{M}+3 \mathrm{H}]^{3+}$ of SNAP-8 was not detected. The intensity of SNAP-8 was monitored with the desolvation line (DL) temperature from a range of 200 to $275^{\circ} \mathrm{C}$. DL temperature was optimized for $[\mathrm{M}+2 \mathrm{H}]^{2+}$ intensity at $200^{\circ} \mathrm{C}$ (Fig. 2). Q3 SCAN spectra of SNAP-8 (a) and IS (b) are shown in Fig. 3. Precursor ions of SNAP-8 $(m / z 538)$ and IS $(m / z 445)$ were fragmented with collision energy, both product ions of SNAP-8 and IS were optimized to $m / z 102,84$, and 144 , respectively. Optimal collision energies were monitored for SNAP-8 $(m / z 102(-30 \mathrm{~V}), \mathrm{m} / z$ 84 $(-48 \mathrm{~V})$, and $m / z 144(-25 \mathrm{~V}))$ and IS $(m / z 102(-39 \mathrm{~V}), m / z 84(-55$ $\mathrm{V})$, and $m / z 144(-30 \mathrm{~V})$ ). Optimized MRM conditions are summarized in Table 2 and MRM chromatograms of SNAP-8 and IS are shown in Fig. 4.

\section{Method validation for SNAP-8 analysis by LC-MS/MS}

SNAP-8 was detected as a single peak at $1.7 \mathrm{~min}$ in extracts of a blank patch spiked with SNAP-8 standard. Chromatograms of SNAP-8 in extracts of blank patch spiked with IS (a), and extracts of blank patch spiked with SNAP-8 and IS (b) are shown in Fig. 4. The good linearity was obtained with correlation coefficient $(r)$ of 0.9971 in the range from 0.0125 to $0.1250 \mathrm{ng} / \mathrm{mg}$. LOD and LOQ were evaluated with diluted standard solution and their levels were 0.0025 and $0.0125 \mathrm{ng} / \mathrm{mg}$, respectively. Repeatability of 0.05 and $0.1 \mathrm{ng} / \mathrm{mg}$ showed 0.20 and 0.02 (\%RSD), respectively. Accuracy were 1.44 and 1.68 (\%RE) at 0.05 and $0.1 \mathrm{ng} / \mathrm{mg}$, respectively. The recovery showed $76.7 \%$ at $0.125 \mathrm{ng} / \mathrm{mg}$ of microneedle of patch (Table 3 ). In the stability test, SNAP- 8 was stable at least $96 \mathrm{~h}$ when this was refrigerated at $4{ }^{\circ} \mathrm{C}$ (Table 4 and Fig. 5). Therefore, this method was suitable for quantification and evaluation test of SNAP in patch products.

\section{Patch matrix effects for SNAP-8 analysis}

Two different calibration curves were compared to assess matrix effects for measurements made using blank

Table 4 Stability test of SNAP-8 in DW at $4^{\circ} \mathrm{C}$

\begin{tabular}{lllll}
\hline Analyte & \multicolumn{4}{l}{ Concentration of SNAP-8 $(0.77 \mathrm{ng} / \mathrm{\mu L})$} \\
\cline { 2 - 4 } & $0 \mathrm{~h}$ & $24 \mathrm{~h}$ & $48 \mathrm{~h}$ & $96 \mathrm{~h}$ \\
\hline SNAP-8 & $0.75 \pm 0.04$ & $0.77 \pm 0.03$ & $0.78 \pm 0.03$ & $0.75 \pm 0.02$ \\
\hline
\end{tabular}




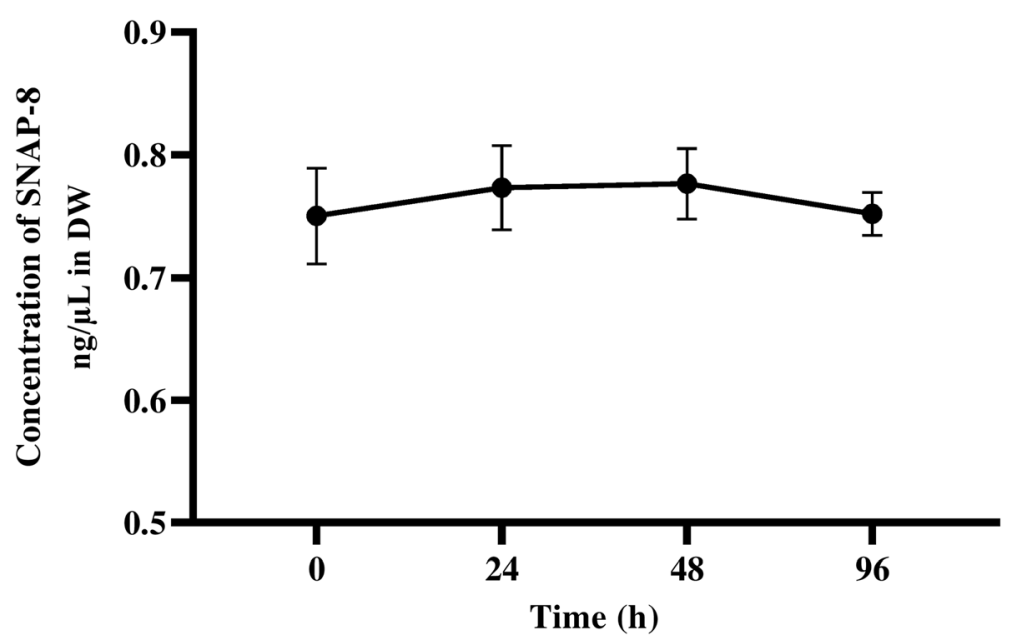

Fig. 5 Stability test of SNAP-8 for $96 \mathrm{~h}$ at $4{ }^{\circ} \mathrm{C}$

patches or HPLC grade water, and SNAP-8 in microneedle patches were quantified. Based on the results of four patches, the calculated SNAP-8 level using HPLC grade water calibration curve was $89.5 \pm 10.5 \mathrm{ng}$, while it was $76.9 \pm 8.6 \mathrm{ng}$ by using matrix calibration curve including blank patches. In this result, the calculated SNAP-8 level using matrix calibration curve was $16.3 \%$ smaller than HPLC grade water-based values. Therefore, the matrix effects of patches must be considered for quantitative analysis of SANP-8.

\section{Conclusion}

Analytical method of SNAP-8 was developed by LC-MS/ MS in MRM mode. In the optimal condition, linearity $(r$ $\geq 0.9971$ ), repeatability (\%RSD $=0.02$ to 0.12 ), accuracy $(\% \mathrm{RE}=-1.68$ to 1.44$)$, and recovery $(76.7 \%)$ showed with LOD of $0.0025 \mathrm{ng} / \mathrm{mg}$ and LOQ of $0.0125 \mathrm{ng} / \mathrm{mg}$. When applied to patch product, SNAP-8 was identified and determined as $76.9 \pm 8.6 \mathrm{ng}$. Therefore, this method was suitable for determination of SNAP-8 in patch products, which will be useful for quality control and evaluation test of SNAP-8 in the cosmetic fields.

\section{Abbreviations \\ SNAP-25: Synaptosome-associated protein of $25 \mathrm{kDa}$; SNAP-8: Acetyl octapeptide-3; BOTOX : Botulinum toxin; LC-MS/MS: Liquid chromatography- tandem mass spectrometry; IS: Internal standard; HPLC: High-performance liquid chromatography; ACN: Acetonitrile; FA: Formic acid; \\ TEA: Trimethylamine; LOD: Limit of detection; LOQ: Limit of quantification: r: Correlation coefficient; \%RSD: Repeatability; \%RE: Accuracy; MRM: Multiple reaction monitoring; ESI: Electrospray ionization; DL: Desolvation line; CID: Collision-induced dissociation; Q1: Quadrupole 1; Q3: Quadrupole 3}

\section{Acknowledgements}

This study was performed at the College of Pharmacy and Research Institute of Life and Pharmaceutical Sciences, Sunchon National University. This work was supported by Raphas Co., Ltd. in 2015.

\section{Authors' contributions}

MJ and H-SL performed method development, optimization, and validation, and were a major contributor in writing the manuscript. SC, SJO, and D-YK performed pre-analytical experiments and sample preparation. YK, CS, JM, and H-JP performed optimization of method. JDK, DHJ, and M-JP designed the experiments and supervised this work. All authors read and approved the final manuscript.

\section{Funding}

Not applicable in this section.

Availability of data and materials

The datasets used and/or analyzed during the current study are available from the corresponding author on reasonable request.

\section{Competing interests}

The authors declare that they have no competing interests.

\section{Author details}

${ }^{1}$ College of Pharmacy, Sunchon National University, Suncheon 540-950, Republic of Korea. ${ }^{2}$ New Drug Development Center, Daegu-Gyeongbuk Medical Innovation Foundation, Daegu, Republic of Korea. ${ }^{3}$ Redone Tech, Laboratories of Marine New Drugs, Seoul, Republic of Korea. ${ }^{4}$ Raphas, Avison Biomedical Research Center, 50-1 Yonsei-ro, Seodaemun-gu, Seoul, Republic of Korea.

Received: 20 April 2020 Accepted: 29 July 2020

Published online: 12 August 2020

\section{References}

Adler M, Sheridan RE, Deshpande SS, Oyler GA. Neuromuscular transmission and muscle contractility in SNAP-25-deficient coloboma mice. Neurotoxicology. 2001;22(6):775-86. https://doi.org/10.1016/50161813X(01)00066-3.

Blanes-Mira C, Clemente J, Jodas G, Gil A, Fernández-Ballester G, Ponsati B, Gutierrez L, Pérez-Payá E, Ferrer-Montiel A. A synthetic hexapeptide (Argireline) with antiwrinkle activity. Int J Cosmet Sci. 2002;24(5):303-10. https://doi.org/10.1046/j.1467-2494.2002.00153.x.

Blasi J, Chapman ER, Link E, Binz T, Yamasaki S, De Camilli P, Südhof TC, Niemann $H$, Jahn R. Botulinum neurotoxin A selectively cleaves the synaptic protein SNAP-25. Nature. 1993;365(6442):160. https://doi.org/10 1038/365160a0.

Gutiérrez LM, Cánaves JM, Ferrer-Montiel AV, Reig JA, Montal M, Viniegra S. A peptide that mimics the carboxy-terminal domain of SNAP-25 blocks Ca2+dependent exocytosis in chromaffin cells. FEBS Lett. 1995;372(1):39-43. https://doi.org/10.1016/0014-5793(95)00944-5. 
Gutierrez LM, Viniegra S, Rueda J, Ferrer-Montiel AV, Canaves JM, Montal M. A peptide that mimics the C-terminal sequence of SNAP-25 inhibits secretory vesicle docking in chromaffin cells. J Biol Chem. 1997;272(5):2634-9. https:// doi.org/10.1074/jbc.272.5.2634.

Lipotec $^{\mathrm{TM}}$. (n.d.) Snap-8, An octave-tide to express yourself at ease. Barcelona, Spain. https://www.cossma.com/fileadmin/all/cossma/Archiv/Productlnfo/ COS1005_14_ProdSnap8.pdf..

Park J-H, Allen MG, Prausnitz MR. Biodegradable polymer microneedles: fabrication, mechanics and transdermal drug delivery. J Control Release. 2005;104(1):51-66. https://doi.org/10.1016/j.jconrel.2005.02.002.

Yamauchi PS, Lowe NJ. Botulinum toxin types A and B: comparison of efficacy, duration, and dose-ranging studies for the treatment of facial rhytides and hyperhidrosis. Clin Dermatol. 2004;22(1):34-9. https://doi.org/10.1016/j. clindermatol.2003.11.005.

Zhang S, Qiu Y, Gao Y. Enhanced delivery of hydrophilic peptides in vitro by transdermal microneedle pretreatment. Acta Pharm Sin B. 2014;4(1):100-4

Zhou W, Wang PG, Krynitsky AJ, Rader JI. Rapid and simultaneous determination of hexapeptides (Ac-EEMQRR-amide and H2N-EEMQRRamide) in anti-wrinkle cosmetics by hydrophilic interaction liquid chromatography-solid phase extraction preparation and hydrophilic interaction liquid chromatography with tandem mass spectrometry. J Chromatogr A. 2011;1218(44):7956-63.

\section{Publisher's Note}

Springer Nature remains neutral with regard to jurisdictional claims in published maps and institutional affiliations.

\section{Submit your manuscript to a SpringerOpen ${ }^{\circ}$ journal and benefit from:}

- Convenient online submission

- Rigorous peer review

- Open access: articles freely available online

- High visibility within the field

- Retaining the copyright to your article

Submit your next manuscript at $\boldsymbol{\nabla}$ springeropen.com 